При разработке и реализации стратегии вуза следует уделять внимание развитию стратегического партнерства. Стратегию управления вузом следует выбирать с позиции взаимодействия вуза с каждой группой заинтересованных сторон [4].

Ключевым инструментом стратегического управления современным университетом должна стать инновационная миссия, задающая общее направление и приоритеты развития инициативных проектных команд преподавателей и научных сотрудников. Он предлагает уникальный подход к университетскому менеджменту и соответственно уникальную организационную структуру, получившую название «проектно-ориентированный университет» [2].

Методы стратегического анализа - это система принципов деятельности образовательной организации, определяющая направления ее стратегического развития. Стратегическое управление как метод управления направлено на достижение определенных стратегических целей. В России федеральные и региональные органы власти широко применяют методы стратегического управления в процессе государственного управления и регулирования [4].

Любая образовательная организация стремится к успешному функционированию, то есть к сохранению перспективы развития и повышению эффективности деятельности. Вуз в условиях неопределённости вынужден постоянно решать различные задачи. В процессе своей жизнедеятельности образовательная организация сталкивается с другими организациями, клиентами, поставщиками, человеческим ресурсом и другими институтами рыночной экономики. Вуз как открытая система имеет связи с внешней средой. При этом для самостоятельного решения различных задач организация должна обладать информацией о субъектах и объектах внутренней и внешней среды [2].

Важным в стратегическом управлении является разработка миссии. Простая, ясная, часто повторяемая и побуждающая к действию формулировка миссии повернет головы в заданном направлении и явится началом нового похода вузовского сообщества. Грамотно сформулированная миссия побуждает к действию, она доводится в ясной и убедительной форме до всех заинтересованных лиц на всех иерархических уровнях, не вызывая никаких сомнений относительно будущего разработанного администрацией курса. Миссия позволяет избежать потери управляющими ориентиров или четкого руководства, она помогает направлять стратегические действия вузовских управляющих более низкого звена в нужное русло, подготавливает вуз к вступлению в будущее [1].

$$
* * *
$$

1. Балобанов, А. Е. Стратегическое планирование развития университета / А. Е. Балобанов, А. К. Клюев // Университетское управление: практика и анализ. - 2002. - №2 (21). - С. 18-27.

2. Егоршин, А. П. Концепция стратегического управления вузом / А. П. Егоршин, Е. Ю. Горбунова // Высшее образование в России. - 2007. - № 10. - С. 31-39.

3. Ищук, Т. Л. Особенности стратегического планирования в высшей школе // Экономика. - 2009. - №3. - С. $157-162$.

4. Кайгородцев, А. А. Концепция стратегии развития вуза в условиях рыночной экономики / А. А. Кайгородцев, Г. Ж. Сарсембаева, Т. Ф. Кайгородцева // Международный журнал экспериментального образования. -2015 . - № 11-3. - С. 379-382.

\title{
Хамурадов М.А. \\ Анализ формирования доходов и расходов Пенсионного фонда РФ
}

ФГБОУ ВО «Чеченский государственный университет им. А.А. Кадырова»

(Россия, Грозньй)

doi: 10.18411/trnio-12-2021-64

\section{Аннотация}

Актуальность данной темы обусловлена проблемами с формированием доходной части Пенсионного фонда страны и реформами, начатыми в 2019 году Правительством РФ. 
В статье проводится анализ доходов и расходов Пенсионного фонда за последние годы. На основе проведенного анализа дается оценка эффективности функционирования Пенсионного фонда, делаются выводы и предложения, направленные на совершенствование пенсионной системы страны.

Ключевые слова: пенсионная система, анализ доходов и расходов, пенсионные накопления.

\section{Abstract}

The relevance of this topic is due to the problems with the formation of the income part of the country's Pension Fund and the reforms initiated in 2019 by the Government of the Russian Federation. The article analyzes the income and expenses of the Pension Fund in recent years. Based on the analysis, the efficiency of the Pension Fund is assessed, conclusions and proposals aimed at improving the country's pension system are made.

Keywords: pension system, income and expense analysis, pension savings.

В последнее время Пенсионный фонд РФ сталкивался с проблемами, связанными с недостатком собственных средств для обеспечения выплат и выполнения своих функциональных обязанностей. Именно с этим и были связаны реформы по повышению возраста пенсионеров, что вызвало большое недовольство среди пожилых граждан страны и способствовало падению рейтинга президента правительства РФ.

За три года (2018-2020 гг.) совокупный трансферт федерального бюджета Пенсионному фонду РФ составит 10 трлн руб. По отношению к ВВП профицит федерального бюджета с учетом трансферта Пенсионного фонда РФ составит в 2018 г. 0,3\%, в 2019 г. - 0,8\%, в 2020 г. - 0,8\% ВВП.

Без такого трансферта профицит будет равен в 2018 г. 3,1\%, в 2019 г. - 2,8\%, в 2020 г. - $2,3 \%$ ВВП.

В табл. 1 представлены основные относительные параметры Пенсионного фонда РФ в 2018-2020 гг. Его доходы без учета трансферта из федерального бюджета должны составить от $5 \%$ до $5,1 \%$ ВВП, а расходы - от $8,1 \%$ до $8,7 \%$ ВВП. Доля трансферта федерального бюджета в расходах Пенсионного фонда РФ составит 38,2-38,4\%, а доля трансферта Пенсионному фонду РФ в расходах федерального бюджета - 19,8-20,4\% (табл. 1).

Таблица 1

Основные относительные параметры Пенсионного фонда РФ на 2018-2020 г2., в \% [1]

\begin{tabular}{|c|c|c|c|}
\hline Параметры бюджета & 2018 & 2019 & 2020 \\
\hline $\begin{array}{c}\text { Доходы Пенсионного фонда РФ (без учета трансферта из } \\
\text { федерального бюджета) к ВВП }\end{array}$ & 5,1 & 5,1 & 5 \\
\hline Расходы Пенсионного фонда РФ к ВВП & 8,7 & 8,4 & 8,1 \\
\hline $\begin{array}{c}\text { Дефицит Пенсионного фонда РФ (без учета трансферта } \\
\text { федерального бюджета) к ВВП }\end{array}$ & $-3,6$ & $-3,3$ & $-3,2$ \\
\hline $\begin{array}{c}\text { Доля трансферта федерального бюджета Пенсионному фонду } \\
\qquad Р \Phi \text { КВВП }\end{array}$ & 3,4 & 3,2 & 3,1 \\
\hline $\begin{array}{c}\text { Доля трансферта федерального бюджета в расходах } \\
\text { Пенсионного фонда РФ }\end{array}$ & 38,4 & 38,4 & 38,2 \\
\hline
\end{tabular}

По данным Федеральной службы государственной статистики, за 18 лет (с 1998 по 2016 г.) увеличилась доля мужчин и женщин, доживающих до возраста выхода на пенсию (для мужчин - 60 лет, для женщин - 55 лет). Если в 1998 г. до 60 лет доживали 59,9\% мужчин, то в 2016 г. - уже 69,4\% (прирост 9,5\%). Это означает, что до пенсионного возраста стали доживать на 15,9\% больше мужчин. У женщин также произошло увеличение доли лиц, доживающих до стандартного возраста выхода на пенсию, но это увеличение носит менее выраженный характер, чем у мужчин. Так, в 1998 г. до 55-летия доживали 88,3\% женщин, а в 2016 г. - 91,1\%. Таким образом, за 18 лет до этого возраста стали доживать женщин на $3,2 \%$ больше. Это связано с наличием у женщин меньшего резерва увеличения 
продолжительности жизни по сравнению с мужчинами из-за общего превышения средней продолжительности жизни женщин по сравнению с мужчинами [3].

В 2016 г. доля мужчин и женщин, доживающих до нового возраста выхода на пенсию (соответственно 65 и 60 лет), была практически равной доле их дожития до 60 и 55 лет в 1998 г. Также росла и ожидаемая продолжительность жизни в России. В 2005 г. она для 60летних мужчин составляла 13,26 года, а в 2017 г. - 16,46 года, что означает увеличение среднего периода пребывания мужчин на пенсии на 3,2 года. У 55-летних женщин ожидаемая продолжительность предстоящей жизни выросла с 22,85 до 26,14 лет (рост на 3,3 года).

Рост продолжительности жизни в России приводит к увеличению численности пенсионеров. Так, если по состоянию на 1 января 2011 г. численность пенсионеров, получающих пенсию по старости, составляла 32,4 млн чел., то спустя семь лет (на 1 января 2018 г.) - 36,3 млн чел [1].

Численность пенсионеров в стране за эти семь лет выросла на 12\%. Увеличение численности пенсионеров происходит за счет их прироста в городской местности, а в сельской местности за последние шесть лет их численность практически не изменилась. Такая ситуация обусловлена общим оттоком населения из сельской местности.

Более высокий возраст выхода мужчин на пенсию по сравнению с женщинами с одновременной более низкой продолжительностью их жизни обусловливает двукратное превышение численности женщин-пенсионеров по сравнению с численностью мужчинпенсионеров.

До принятия закона, ограничивающего индексацию пенсий для работающих пенсионеров, каждый третий пенсионер официально был работающим, то есть одновременно получал пенсию и заработную плату. После принятия данного закона численность таких пенсионеров сократилась в полтора раза.

Для бюджетной системы страны повышение пенсионного возраста носит позитивный характер, так как решает проблему обеспечения сбалансированности федерального бюджета. В связи с этим можно ожидать снижения дефицита и/или повышения профицита федерального бюджета в будущем и снижения рисков, связанных с возможным ростом государственного долга. Это будет реализовываться только в условиях ответственной бюджетной политики. Не существует гарантий того, что правительства в будущем значительно расширят бюджетные расходы, включив в бюджет дополнительные социальные и экономические программы.

Говоря о реформах пенсионного фонда, сторонники увеличения пенсионного возраста, утверждают, что это необходимо в условиях демографической ямы, что делается для сбалансирования экономически активного и нетрудоспособного населения. Считается, что повышение пенсионного возраста даже на 1-2 года, может привести к значительному сокращению расходов на выплаты пенсий и будет иметь в долгосрочном плане высокий положительный эффект.

Обычно к среднесрочному плану относят период 3-5 лет, и рамках среднесрочного периода к отрицательному развитию социальной и экономической ситуации могут привести и другие факторы. При оценке ситуации в стране необходимо учитывать, что увеличение темпов экономически активного населения должно выравниваться с таким же объемом и рабочих мест в стране, которое в свою очередь зависит от инвестиционной политики.

Следует заметить, что такой рост инвестиций сам по себе может обеспечить повышение производительности труда без необходимости прироста рабочей силы, что не потребует увеличения возраста выхода на пенсию. В экономической политике следует приоритет отдавать росту ВВП не за счет экстенсивных, а за счет интенсивных инвестиций. Хотя на практике легче реализовать рост экономики за счет экстенсивных факторов, что и потребовало увеличения возраста выхода граждан на пенсию. 
Рост численности экономически активного населения может привести к проблеме снижения предельной отдачи от использования трудовых ресурсов. Этот вывод можно сделать исходя из постулатов экономической теории о действии закона убывающей предельной производительности.

В целом, можно сделать вывод о том, что в России существует четко выраженная тенденция увеличения срока дожития граждан, что приводит к увеличению численности пенсионеров и увеличению финансовой нагрузки на федеральный бюджет и Пенсионный фонд РФ. Трансферт Пенсионному фонду РФ является значительным и приводит к дефициту федерального бюджета, что требует проведения работы по восстановлению сбалансированности федерального бюджета в будущем.

Данные цели также могут быть достигнуты за счет большего перераспределения природной ренты между частным сектором и государством, а также переход на прогрессивную систему налогообложения, увеличения ставки налога на прибыль и ее дифференциации для различных отраслей. Кроме того, до сих пор является актуальной проблема повышения эффективности бюджетных расходов.

$$
* * *
$$

1. Соловьев А.К. Пенсионная реформа в условиях бюджетного кризиса: риски роста бедности // ЭКО. 2017. №8. С. 139-153.

2. Официальный сайт Пенсионного фонда РФ. [Электронный ресурc]: http://www.pfrf.ru

\begin{tabular}{l} 
3. Официальный сайт Федеральной службы государственной статистики. [Электронный ресурс]: \\
\hline
\end{tabular} https://rosstat.gov.ru/

\section{Шалманова В.А., Ильясова А.В. \\ Тенденции и возможности устойчивого развития малого бизнеса в условиях цифровизации}

Пензенский государственный технологический университет

(Россия, Пенза)

doi: 10.18411/trnio-12-2021-65

\section{Аннотация}

В условиях высокой степени неопределенности предпринимательской деятельности резко возрастает интерес к проблемам обеспечения устойчивого развития предприятий, их способности быстро и эффективно диагностировать и преобразовывать работу, адекватно реагируя на изменения внешней и внутренней среды в эпоху цифровой экономики.

Ключевые слова: цифровая экономика, кадровое обеспечение, финансовый менеджмент, финансовая политика, цифровые платформы, устойчивое развитие.

\section{Abstract}

In conditions of high uncertainty of business activity, there is a sharp increase in interest in the problems of ensuring sustainable development of enterprises, their ability to quickly and effectively diagnose and transform their work, adequately responding to changes in the external and internal environment in the era of the digital economy.

Keywords: digital economy, human resources, financial management, financial policy, digital platforms, sustainable development.

Внедрение цифровых технологий во всех сферах является важнейшим условием устойчивого развития страны.

Цифровизация экономики необходима для создания удобных платформ для комфортного взаимодействия государства и предприятий, снижения налоговой нагрузки на 